\title{
Hearing requires otoferlin-dependent efficient replenishment of synaptic vesicles in hair cells
}

\author{
Tina Pangršič ${ }^{1}$, Livia Lasarow ${ }^{2}$, Kirsten Reuter $^{3,9}$, Hideki Takago $^{1,9}$, Martin Schwander $^{4}$, Dietmar Riedel ${ }^{5}$, \\ Thomas Frank $^{1}$, Lisa M Tarantino ${ }^{6}$, Janice S Bailey ${ }^{6}$, Nicola Strenzke ${ }^{2}$, Nils Brose ${ }^{7}$, Ulrich Müller ${ }^{4}$, \\ Ellen Reisinger ${ }^{3} \&$ Tobias Moser ${ }^{1,8}$
}

Inner hair cell ribbon synapses indefatigably transmit acoustic information. The proteins mediating their fast vesicle replenishment (hundreds of vesicles per $\mathrm{s}$ ) are unknown. We found that an aspartate to glycine substitution in the $\mathrm{C}_{2} \mathrm{~F}$ domain of the synaptic vesicle protein otoferlin impaired hearing by reducing vesicle replenishment in the pachanga mouse model of human deafness DFNB9. In vitro estimates of vesicle docking, the readily releasable vesicle pool (RRP), $\mathrm{Ca}^{2+}$ signaling and vesicle fusion were normal. Moreover, we observed postsynaptic excitatory currents of variable size and spike generation. However, mutant active zones replenished vesicles at lower rates than wild-type ones and sound-evoked spiking in auditory neurons was sparse and only partially improved during longer interstimulus intervals. We conclude that replenishment does not match the release of vesicles at mutant active zones in vivo and a sufficient standing RRP therefore cannot be maintained. We propose that otoferlin is involved in replenishing synaptic vesicles.

At the first auditory synapse in mammals, one ribbon-type active zone of the inner hair cell (IHC) drives one postsynaptic spiral ganglion neuron (SGN) to spike at rates exceeding $100 \mathrm{~Hz}$ in silence and $1 \mathrm{kHz}$ on sound onset ${ }^{1,2}$. Moreover, SGNs sustain firing rates of several hundred hertz during ongoing acoustic stimulation. In such a steady state, vesicle replenishment has to balance vesicle fusion at the IHC active zone. Accordingly, high rates of initial and sustained exocytosis have been found in hair cells ${ }^{3-8}$. Ribbon-type active zones of IHCs replenish readily releasable vesicles at hundreds of hertz over several seconds of stimulation, faster than ribbon synapses in the eye $\mathrm{e}^{9-15}$ and most non-ribbon-type active zones ${ }^{16}$ (but see ref. 17). This efficient vesicle re-supply maintains a large standing pool of fusion-competent synaptic vesicles, which appears to be critical for reliable and temporally precise sound encoding ${ }^{18-20}$.

$\mathrm{Ca}^{2+}$ stimulates vesicle re-supply at presynaptic active zones $^{4,8,21,22}$, but the molecular basis underlying the unique replenishment capacity of IHCs remains unclear. One candidate for this function is the multi- $\mathrm{C}_{2}$ domain protein otoferlin. Otoferlin has been implicated in synaptic vesicle fusion in $\mathrm{IHCs}^{23}$, as $\mathrm{Ca}^{2+}$ dependent exocytosis is largely abolished in IHCs of otoferlin knockout mice $\left(\mathrm{Otof}^{-/-}\right.$), and has been shown to interact with SNARE proteins ${ }^{23}$ and Myosin VI ${ }^{24,25}$.

We studied the effects of a partial loss of otoferlin function from the molecular to the systems level using deaf pachanga mice
$\left(O t o f^{P g a / P g a}\right)^{26}$, which carry a $N$-ethyl-N-nitrosourea-mediated Otof missense mutation (D1767G in NP_001093865, NCBI). Otoferlin protein levels were reduced in IHCs of Otof ${ }^{P g a / P g a}$ mice. We explored synaptic transmission at the IHC synapse in vitro using pre- or postsynaptic patch clamp, $\mathrm{Ca}^{2+}$ uncaging and $\mathrm{Ca}^{2+}$ imaging, and in vivo by recording auditory-evoked population responses and single neuron spiking. We found that deficient vesicle replenishment underlies the hearing impairment of Otof ${ }^{P g a / P g a}$ mice and propose that otoferlin confers the high capacity for vesicle re-supply to the IHC synapse.

\section{RESULTS}

Synaptic hearing loss: normal fusion, slowed replenishment Otof ${ }^{P g a / P g a}$ mice lacked auditory brainstem responses even when probed by very loud sounds ( $120 \mathrm{~dB}$; Fig. 1a), but showed a small potential around the click stimulus, which probably reflected the summed potentials of hair cells. We observed distortion products of otoacoustic emissions with normal amplitude (data not shown), corroborating the notion of intact cochlear amplification ${ }^{26}$. To further narrow down the site of defect, we studied cochlear function by electrocochleography. Cochlear microphonics, reflecting hair cell mechanoelectrical transduction, were readily observed with amplitudes comparable to those of wild-type mice $\left(\mathrm{Otof}^{+/+}\right.$; Fig. 1b). The summating potential, which is thought to primarily

\footnotetext{
${ }^{1}$ InnerEarLab, Department of Otolaryngology and Center for Molecular Physiology of the Brain, University Medical Center Göttingen, Göttingen, Germany. ${ }^{2}$ Auditory Systems Physiology group, Department of Otolaryngology, University Medical Center Göttingen, Göttingen, Germany. ${ }^{3}$ Molecular Biology of Cochlear Neurotransmission group, Department of Otolaryngology, University Medical Center Göttingen, Göttingen, Germany. ${ }^{4}$ Department of Cell Biology, Institute for Childhood and Neglected Diseases, The Scripps Research Institute, La Jolla, California, USA. ${ }^{5}$ Laboratory of Electron Microscopy, Max Planck Institute for Biophysical Chemistry, Göttingen, Germany. ${ }^{6}$ Department of Psychiatry, University of North Carolina, Chapel Hill, North Carolina, USA. ${ }^{7}$ Department of Molecular Neurobiology, Max Planck Institute of Experimental Medicine and Center for Molecular Physiology of the Brain, Göttingen, Germany. ${ }^{8}$ Bernstein Center for Computational Neuroscience, University of Göttingen, Göttingen, Germany. ${ }^{9}$ These authors contributed equally to this work. Correspondence should be addressed to T.M. (tmoser@gwdg.de) or E.R. (ereisin@gwdg.de).
} 

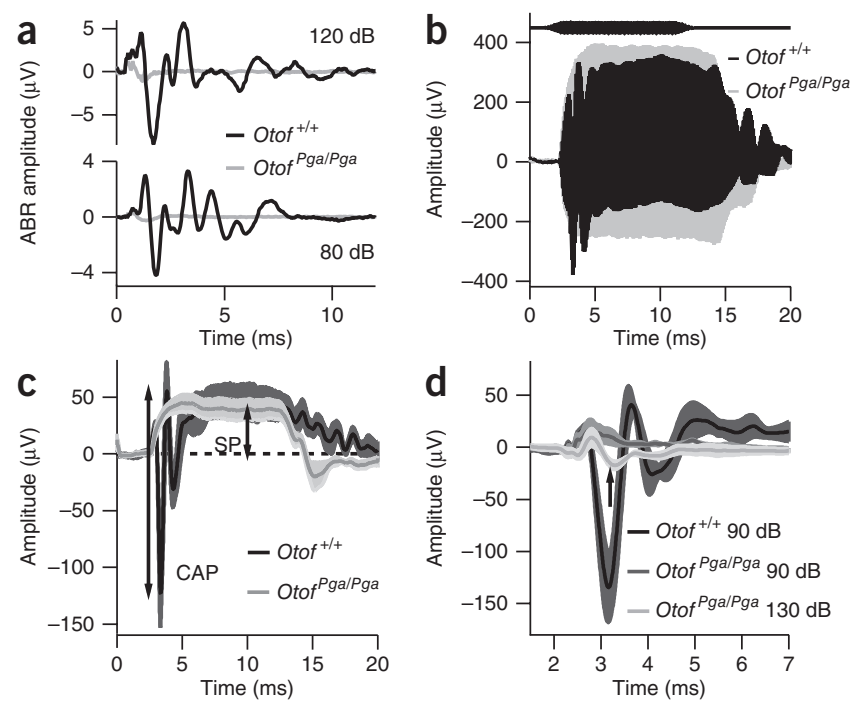

indicate the summed IHC receptor potential, was maintained in

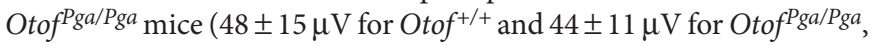
$n=6$ each; Fig. 1c), suggesting that IHC transduction and basolateral conductance were normal. However, we did not observe obvious compound action potentials even at a click stimulation of $130 \mathrm{~dB}$ (Fig. 1d). We conclude that the defect causing the hearing impairment of Otof ${ }^{P g a / P g a}$ mice is located downstream of IHC receptor

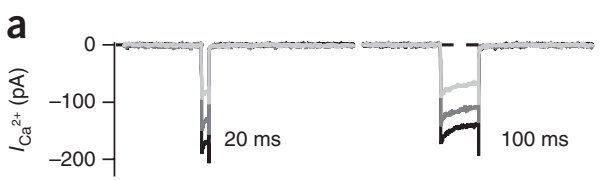

Figure 1 Otof Pga/Pga mice have normal hair cell transduction and receptor potentials, but severe hearing impairment. (a) No auditory brainstem responses (ABR) were elicited by $120-\mathrm{dB}$ (top) and $80-\mathrm{dB}$ (bottom) click stimuli in 2-4-week-old Otof PgalPga mice (average traces), whereas normal responses were seen in $\mathrm{Otof}^{+1+}$ (representative examples) mice. (b) Electrocochleography. Representative traces in response to 12-ms, 90-dB, 12-kHz tone bursts (indicated by top trace) recorded at high bandwidth are shown, illustrating the presence of large cochlear microphonics in Otof PgalPga and $\mathrm{Otof}^{+1+}$ mice. The spiral ganglion compound action potential (CAP, visible for $\mathrm{Otof}^{+/+}$at the onset of the tone) is missing in the Otof PgalPga mouse. (c) Averages ( \pm s.e.m.) of low pass-filtered ( $3 \mathrm{kHz}$ ) electrocochleography traces in response to $12-\mathrm{ms}, 90-\mathrm{dB}, 12-\mathrm{kHz}$ tone bursts for Otof PgalPga and $\mathrm{Otof}^{+/+}$mice. We found normal summating potential (SP), but no CAP, in Otof PgalPga mice. (d) For clicks at a stimulus level of $130 \mathrm{~dB}$, a small putative negative potential becomes apparent (arrow) in the Otof PgalPga mice $(n=3)$, potentially representing a residual spiral ganglion CAP (absent for 90-dB click stimulation).

potential generation, most likely at the IHC synapse. We did not test auditory nerve function by electrical stimulation in Otof ${ }^{P g a / P g a}$ mice, but electrically evoked auditory brainstem responses have been observed in tof $^{-1-}$ mice ${ }^{23}$.

Next, we performed patch-clamp measurements of $\mathrm{Ca}^{2+}$ currents and membrane capacitance to study presynaptic function in apical IHCs of Otof ${ }^{\mathrm{Pga} / \mathrm{Pga}}$, Otof $\mathrm{Pgal}^{-}$, Otof ${ }^{-/-}$and Otof $\mathrm{f}^{+/+}$mice (Fig. 2a,b). Unexpectedly, we found normal exocytic membrane capacitance increments $\left(\Delta C_{\mathrm{m}}\right)$ for depolarizations lasting up to $10 \mathrm{~ms}$ in IHCs of Otof ${ }^{P g a / P g a}$ and Otof ${ }^{P g a /-}$ mice (Fig. 2b), indicating normal exocytosis of the RRP ${ }^{4}$ at interstimulus intervals of at least $30 \mathrm{~s}$. We then fitted the
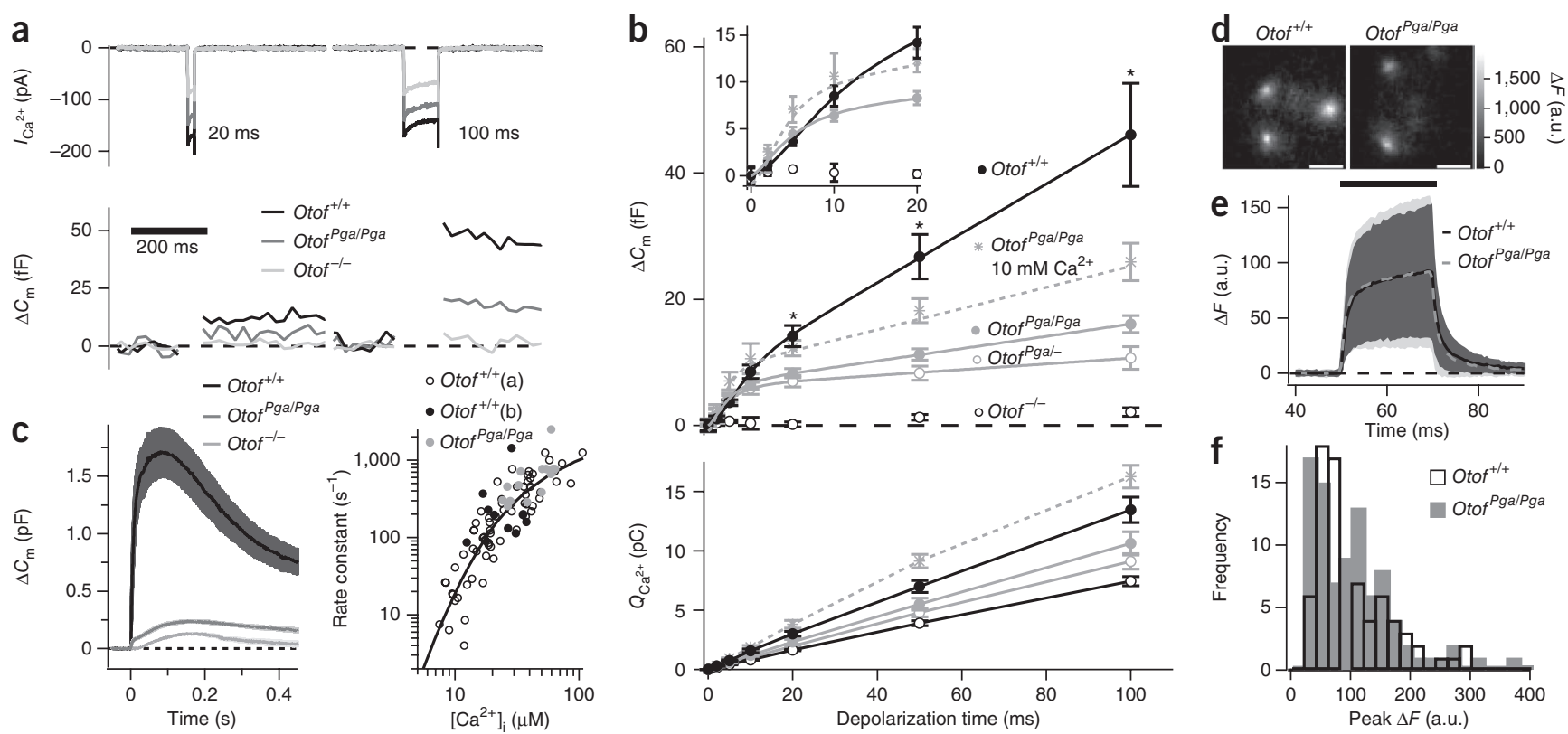

Figure 2 Normal vesicle fusion and impaired vesicle replenishment in Otof Pga/Pga IHCs. (a) Representative Ca ${ }^{2+}$ currents (top) and low pass-filtered $C_{m}$ changes (bottom) recorded from Otof ${ }^{+/}$, Otof Pga/Pga and Otof $/-1$ HCs in response to 20-ms (left) and 100-ms (right) depolarizations. (b) Mean ( \pm s.e.m.) exocytic $\Delta C_{\mathrm{m}}$ (top) and $\mathrm{Ca}^{2+}$ current integrals (bottom) of Otof ${ }^{+/+}(n=8)$, Otof Pga/Pga $(n=14)$, Otof Pga/- $(n=13)$ and Otof ${ }^{/-}(n=7) \mathrm{IHCs}^{\mathrm{H}}$ as a function of stimulus duration. In addition, data from OtofPga/Pga IHCs bathed in elevated $\left[\mathrm{Ca}^{2+}\right]_{\mathrm{e}}(10 \mathrm{mM}, n=7)$ are shown. Lines represent least-square fits to the data (Table 1). Inset shows the first $20 \mathrm{~ms}$ on an expanded scale. ${ }^{*} P<0.05$. (c) Average $\Delta C_{\mathrm{m}}$ traces ( \pm s.e.m.) of Otof ${ }^{+/+}(n=7)$, OtofPga/Pga $(n=10)$ and Otof $^{--}(n=7) \mathrm{lHCs}$ recorded during $\mathrm{Ca}^{2+}$ uncaging $(0 \mathrm{~ms}$ indicates time of flash, see Table 1 for fit parameters). Right, rate constants of the fast exocytic component as a function of postflash $\left[\mathrm{Ca}^{2+}\right]_{\mathrm{i}}$ in OtofPga/Pga and wild-type IHCs (Otoft/+; our data are shown in b, data from ref. 48 are shown in a). The line represents the fit of a fifth-order model with a cooperativity factor of 0.4 (see ref. 48). (d) Representative hotspots of Fluo- $5 \mathrm{~N}$ fluorescence ( $\mathrm{Ca}^{2+}$ microdomains) in IHCs of Otoft/+ and Otof Pga/Pga mice during depolarization to $-7 \mathrm{mV}$. Scale bar represents $2 \mu \mathrm{m}$. (e) Mean and s.d. of background-subtracted Fluo-5N fluorescence recorded by spot detection in the center of the $\mathrm{Ca}^{2+}$ microdomain ${ }^{28}$ (81 domains in $23 \mathrm{Otof+/+}$ IHCs, black line and dark gray area, and 88 domains in 24 Otof Pga/Pga IHCs, gray dashed line and light gray area). (f) Distribution of $\mathrm{Ca}^{2+}$ microdomain peak $\Delta F$ of the same IHCs. 
ARTICLES

Table 1 Quantification of exocytosis

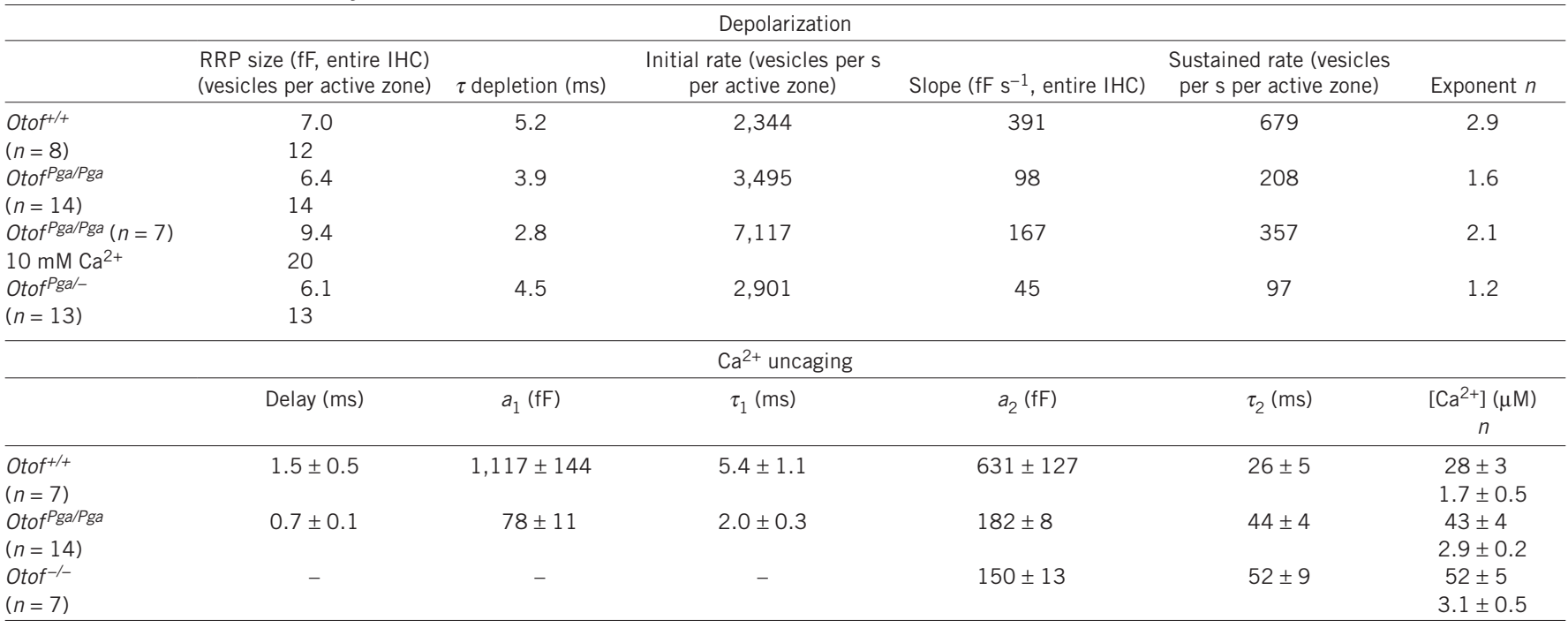

Parameters of depolarization-induced exocytosis were estimated by least-squares fitting.

$$
\Delta C_{m}(t)=R R P_{-} \text {size } \cdot\left(1-e^{-t / \tau}\right)^{n}+\text { slope } \cdot t
$$

where $t$ denotes the duration of depolarization and $\tau$ is the time constant for RRP depletion. The RRP size (in vesicles per active zone) was estimated as the amplitude of the exponential function divided by the product of synapse number and vesicle capacitance $(\sim 45 \mathrm{aF})^{47}$. Initial and sustained rates of exocytosis (in vesicles per s per active zone) were calculated from the capacitance data as follows:

Initial rate $=\mathrm{RRP}$ size (in $\mathrm{fF}) \div$ number of synapses $\div$ vesicle capacitance $\div \tau$, Sustained rate $=$ slope $\div$ number of synapses $\div$ vesicle capacitance

Vesicles in electron micrographs from Otof ${ }^{+/+}$and Otof Pga/Pga mice were of comparable size (data not shown). Parameters of exocytosis during $\mathrm{Ca}^{2+}$ uncaging were estimated by least-squares fitting. For the Otof ${ }^{+/+}$and Otof Pga/Pga data,

$$
\Delta C_{m}(t)=a_{1} \cdot\left(1-e^{-(t-\text { delay })} / \tau_{1}\right)+a_{2} \cdot\left(1-e^{-(t-\text { delay })} / \tau_{2}\right)^{n} .
$$

For the Otof ${ }^{-/-}$data, $\Delta C_{m}(t)=a_{2} \cdot\left(1-e^{-t / \tau_{2}}\right)^{n}$. Data are presented as mean \pm s.e.m. (where available).

mean $\Delta C_{\mathrm{m}}$ values obtained for different stimulus durations using the sum of an exponential and a linear function to estimate the amount and kinetics of RRP exocytosis and the rate of sustained exocytosis, respectively (Fig. 2b and Table $\mathbf{1})^{4,27}$. RRP size and exocytosis kinetics were normal at active zones of Otof ${ }^{P g a / P g a}$ mice (Table 1), in marked contrast with the near-complete lack of RRP exocytosis in IHCs of Otof ${ }^{-/-}$mice (Fig. 2a,b and ref. 23), which showed significant exocytosis only for depolarizations of $100 \mathrm{~ms}$ and longer $(P<0.01$, data from ref. 23$)$.

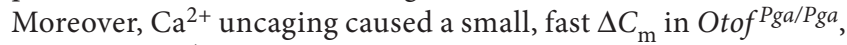
but not in $\mathrm{Otof}^{-/-}$, IHCs (Fig. 2c and Table 1). Potential reasons for the marked amplitude reduction of the flash photolysis-induced $\Delta \mathrm{C}_{\mathrm{m}}$ in Otof ${ }^{P g a / P g a}$, which was still larger than the $\mathrm{Ca}^{2+}$ influxtriggered RRP exocytosis by one order of magnitude, could include fewer docked and primed vesicles outside of active zones. The rate constants of the remaining fast component of Otof ${ }^{P g a / P g a} \mathrm{IHCs}$ at a given postflash intracellular $\mathrm{Ca}^{2+}$ concentration $\left(\left[\mathrm{Ca}^{2+}\right]_{\mathrm{i}}\right)$ were comparable to those of $\mathrm{Otof}^{+/+} \mathrm{IHCs}$, which is consistent with the notion of an unaltered $\mathrm{Ca}^{2+}$-dependent fusion reaction (Fig. 2c and Table 1). Confocal $\mathrm{Ca}^{2+}$ imaging showed IHC synaptic $\mathrm{Ca}^{2+}$ microdomains ${ }^{28}$ with normal amplitude and size as well as nearnormal kinetics (Fig. 2d-f and Supplementary Table 1). Thus, we attribute the small reduction of the $\mathrm{Ca}^{2+}$ influx in Otof ${ }^{P g a / P g a}$ IHCs (20\%; Fig. 2a,b) to the similarly decreased number of synapses (19\%) assessed by immunohistochemistry (Otof Pga/Pga, $10.4 \pm 0.7$ synapses per IHC, $n=357$ IHCs; Otof ${ }^{+/+}, 12.8 \pm 0.3$ synapses per IHC, $n=180$ IHCs; Supplementary Fig. 1 and Supplementary Table 2). In summary, our findings indicate that presynaptic $\mathrm{Ca}^{2+}$ signaling, RRP size and vesicle fusion are intact at active zones of Otof Pga/Pga $^{\mathrm{IHC}}$ under the chosen in vitro conditions.
However, beyond $10 \mathrm{~ms}$ of depolarization, the capacitance rise proceeded much more slowly in Otof ${ }^{P g a / P g a}$ and Otof Pga/- IHCs. This sustained exocytosis after release of the RRP is thought to primarily represent the rate-limiting re-supply of vesicles to the RRP and their subsequent fusion during continued $\mathrm{Ca}^{2+}$ influx ${ }^{5,8,29-31}$, but a potential contribution of fusion-competent vesicles that are released more slowly cannot be ruled out. Here, we assumed that sustained exocytosis primarily reports re-supply to the RRP and estimated its rate as the slope of a linear function (fitted to the data of Fig. 2b). The mean vesicle supply was diminished from 700 vesicles per s per active zone in $\mathrm{Otof}^{+/+}$to 200 vesicles per s per active zone in $O$ tof ${ }^{P g a / P g a}$ and 100 vesicles per s per active zone in Otof ${ }^{\mathrm{Pga} /-}$ IHCs (Fig. $2 \mathbf{b}$ and Table 1). Increasing the $\mathrm{Ca}^{2+}$ influx beyond that of Otof ${ }^{+/+}$IHCs by elevating the extracellular $\mathrm{Ca}^{2+}$ concentration $\left(\left[\mathrm{Ca}^{2+}\right]_{\mathrm{e}}\right)$ enhanced sustained exocytosis in Otof ${ }^{\mathrm{Pga} / \mathrm{Pga}} \mathrm{IHCs}(360$ vesicles per s per active zone). This indicates that the mutation does not abolish the $\mathrm{Ca}^{2+}$ dependence of vesicle supply and that the replenishment defect can be partially overcome by increasing $\mathrm{Ca}^{2+}$ influx.

The fact that RRP size was normal after resting the synapse for more than $30 \mathrm{~s}$ and that vesicle re-supply was reduced during ongoing stimulation prompted us to explore RRP recovery from depletion using paired-pulse experiments (Fig. 3a). RRP recovery, assessed as the paired-pulse ratio for different interpulse intervals, was impaired in Otof ${ }^{P g a / P g a}$ mice (Fig. 3b). This suggests that there is also a deficit in vesicle replenishment in the rest period between stimuli. Trains of ten short $(10 \mathrm{~ms})$ depolarizations, applied after a period of rest ( 30 -s voltage clamp at $-84 \mathrm{mV}$ ), elicited a $\Delta C_{\mathrm{m}}$ pattern that was indicative of normal RRP exocytosis, but subsequent failure (Fig. 3c). Studying the $C_{\mathrm{m}}$ decline after exocytosis, we observed normal endocytic membrane retrieval (Fig. 3d). 
a
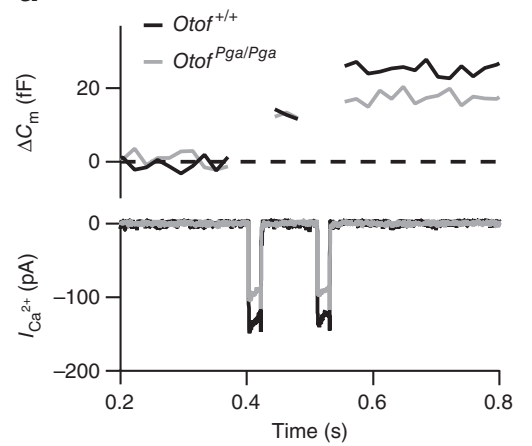

b

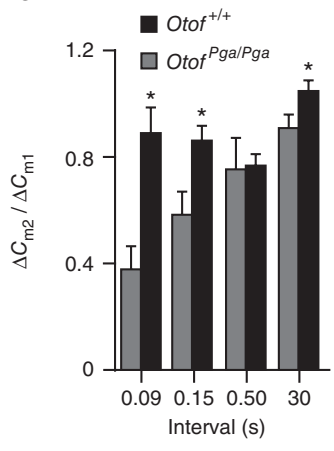

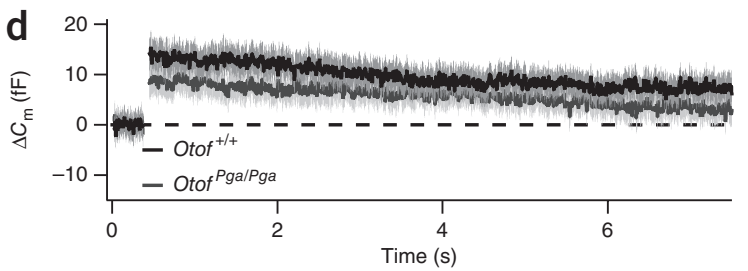

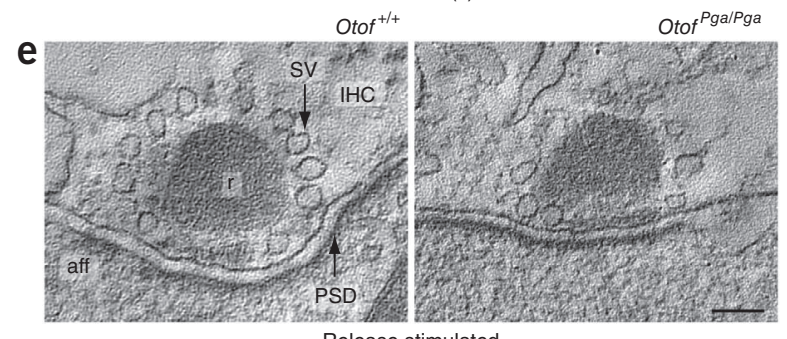

Release stimulated

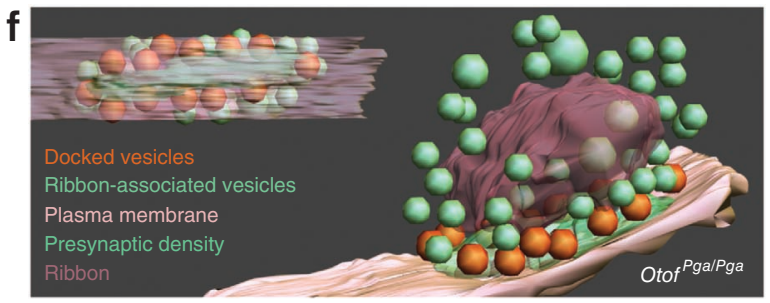

C

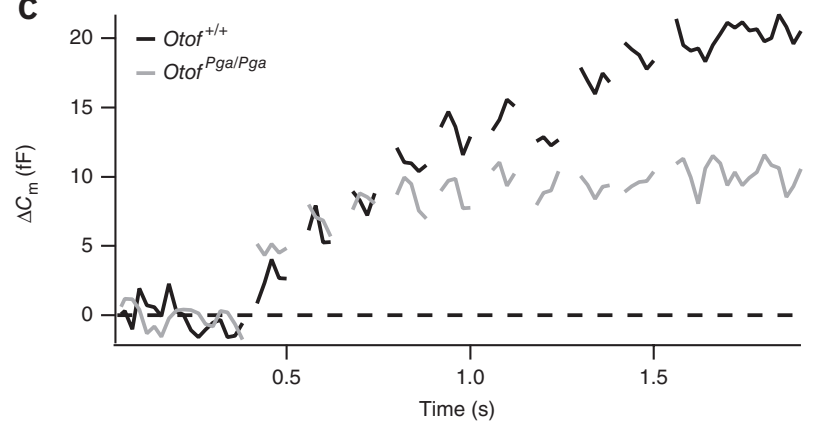

Figure 3 Fatigue of exocytosis, slowed RRP refilling are seen in OtofPga/Pga IHCs, but docking and endocytic membrane retrieval are unaltered. (a) Representative low pass-filtered $\Delta C_{\mathrm{m}}$ traces (top) and $\mathrm{Ca}^{2+}$ currents (bottom) obtained in Otoft/+ and Otof Pga/Pga IHCs in response to a pair of 20-ms depolarizations to $-14 \mathrm{mV}$, which were separated by $89 \mathrm{~ms}$. (b) Mean ratios of exocytic $\Delta C_{\mathrm{m}}$ ( \pm s.e.m.) in response to the second depolarization $\left(\Delta C_{\mathrm{m} 2}\right)$ over the first $\left(\Delta C_{\mathrm{m} 1}\right)$ as a function of interstimulus interval for Otof ${ }^{+/+}(n=13)$ and Otof ${ }^{P g a / P g a}(n=15) \mathrm{IHCs}$. ${ }^{*} P<0.05$.

(c) Average $\Delta C_{m}$ traces recorded in response to $8-\mathrm{Hz}$ trains of 10 -ms depolarizations in Otoft/+ and OtofPga/Pga IHCs. (d) Mean endocytic membrane

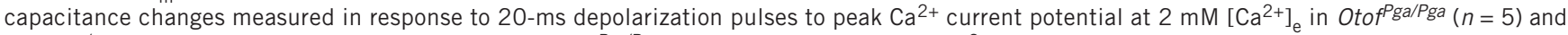

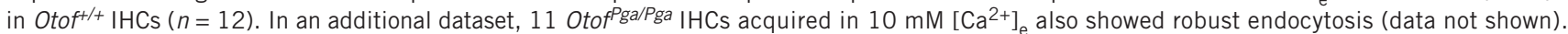
(e) Tomogram sections of ribbon synapses in Otoft/+ (left) and OtofPga/Pga (right) IHCs fixed in stimulatory conditions. (f) Three-dimensional model of an Otof Pga/Pga synapse fixed in stimulatory conditions seen from the synaptic cleft (left) and the side (right). Scale bar represents $100 \mathrm{~nm}$.

\section{Normal synaptic ultrastructure in Otof Pga/Pga IHCs}

To determine whether a docking or a priming defect underlies the impairment of vesicle replenishment at Otof ${ }^{P g a / P g a}$ IHC synapses, we studied their ultrastructure using electron microscopy. Both electron microscopy of single ultrathin sections (perpendicular to the plasma membrane and the long axis of the ribbon; Supplementary Fig. 2) and electron tomography (Fig. $\mathbf{3 e}-\mathbf{f}$ and Supplementary Movies 1 and 2) were performed. Organs of Corti were chemically fixed after either prolonged stimulation $\left(40 \mathrm{mM}\left[\mathrm{K}^{+}\right]_{\mathrm{e}}\right.$ and $5 \mathrm{mM}$ $\left[\mathrm{Ca}^{2+}\right]_{\mathrm{e}}$ ) or inhibition (nominally $\mathrm{Ca}^{2+}$ free, $5 \mathrm{mM}[\mathrm{EGTA}]_{\mathrm{e}}$ and $5 \mathrm{mM}\left[\mathrm{K}^{+}\right]_{\mathrm{e}}$ ) of exocytosis. We quantified the number of membraneproximal vesicles (docked, see below) and total ribbon-associated vesicles in electron micrographs of mid-synaptic ultrathin sections of each group (Supplementary Fig. 2 and Supplementary Table 3). We found a significant reduction in the mean number of membrane-proximal vesicles per ribbon synapse section in stimu-

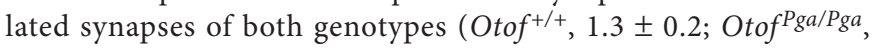
$1.5 \pm 0.1 ; n=27$ and 41 synapses, respectively) when compared with inhibiting conditions $\left(\right.$ Otof $^{+/+}, 1.8 \pm 0.1$; Otof $P g a / P g a, 1.9 \pm 0.1$; $n=36$ and 31 synapses, respectively; $P<0.05$ for both genotypes). However, we did not detect significant differences in the number of membrane-proximal vesicles between $\mathrm{Otof}^{\mathrm{Pga} / \mathrm{Pga}}$ and $\mathrm{Otof}^{+/+} \mathrm{IHC}$ synapses in either inhibitory $(P=0.26)$ or stimulatory $(P=0.26)$ conditions (Supplementary Fig. 2 and Supplementary Table 3).

We used high-resolution electron tomography (Fig. 3e,f) to measure the distance of membrane-proximal synaptic vesicles (Fig. 3f) from the plasma membrane under both conditions. The average membrane-membrane distance was approximately $6 \mathrm{~nm}$ regardless of condition or genotype (Supplementary Table 3), which is compatible with the notions that the membrane-proximal vesicles were physically docked and that vesicle docking is intact at Otof ${ }^{P g a / P g a} \mathrm{IHC}$ synapses even during continuous strong stimulation. Although we cannot completely rule out a trafficking/docking phenotype that may have been masked by strong stimulation compensating for the otoferlin defect, we prefer the interpretation that impaired priming underlies the defective vesicle replenishment.

\section{Reduced rates and maintained size variability of EPSCS}

The stark contrast between the absence of auditory neuron population responses in vivo (Fig. 1) and normal RRP exocytosis after sufficient resting reported by $C_{\mathrm{m}}$ measurements in vitro in Otof ${ }^{\mathrm{Pga} / \mathrm{Pga}}$ mice led us to test postsynaptic function. We made patch-clamp recordings from postsynaptic boutons of SGNs in mice with different Otof genotypes at postnatal day 8-10 (Fig. 4). These measurements revealed the occurrence of excitatory postsynaptic currents (EPSCs) of variable size and shape in Otof ${ }^{P g a / P g a}$ mice, although at lower rates when compared with $\mathrm{Otof}^{+/+}$mice (Fig. 4a,b). We pooled the data from recordings in 5.8 and $40 \mathrm{mM}\left[\mathrm{K}^{+}\right]_{\mathrm{e}}$, as previous work ${ }^{8,32,33}$ has shown that the mean EPSC amplitude is stimulus independent in rat SGNs. As in immature rat SGNs, we found a substantial fraction of multiphasic EPSCs in mice of both genotypes (10\% of 644 EPSCs in Otof ${ }^{+/+}$and $16 \%$ of 279 EPSCs in Otof $\left.{ }^{P g a / P g a}\right)$. Monophasic EPSCs of Otof ${ }^{P g a / P g a}$ 
d

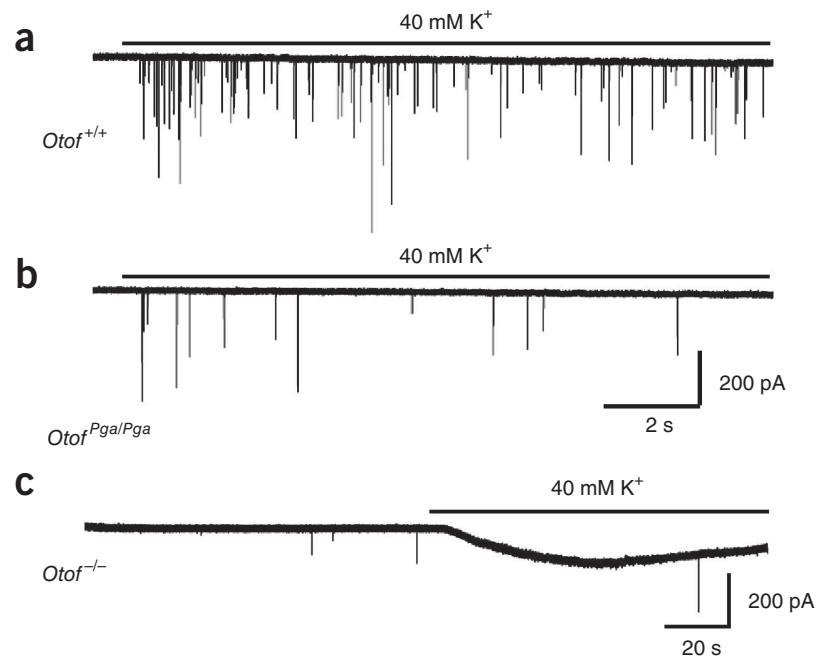

Figure 4 Synchronized multivesicular release and spike generation in otoferlin mutants. (a-c) Whole-cell voltage-clamp recordings of postsynaptic EPSCs in representative $\operatorname{Otof}^{+/+}(\mathbf{a}), \operatorname{Otof}_{\text {Pga/Pga }}(\mathbf{b})$ and $\mathrm{Otof}^{--}$(c) boutons. The bar indicates bath perfusion of stimulatory $40 \mathrm{mM} \mathrm{K}^{+}$saline, which evoked EPSCs at a reduced rate, but with

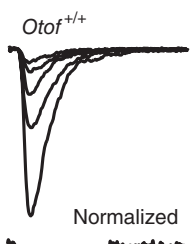

e Otof Pga/Pga f
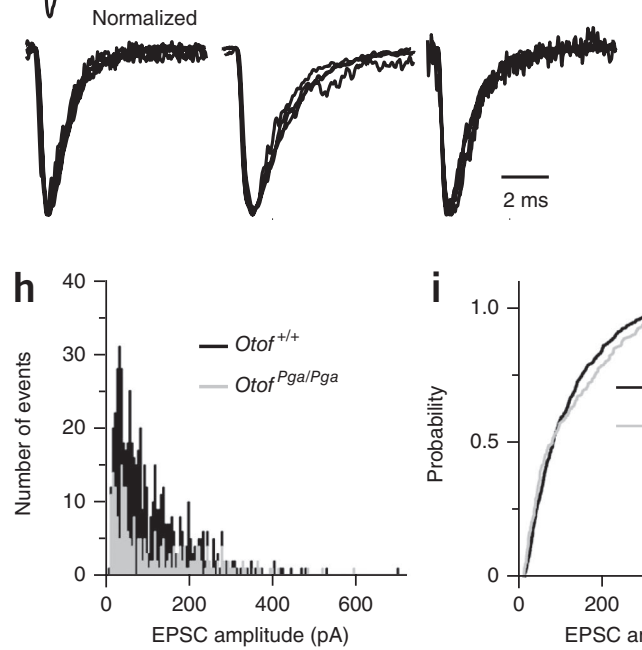

g
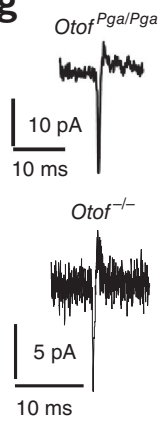

size variability, in Otof Pga/Pga (note the different time scale in c) and Otof ${ }^{-}$. (d-f) Enlarged absolute (top) and normalized (bottom) EPSCs: kinetically homogeneous, but variably sized, EPSCs. (g) Action currents recorded from terminals of Otof Pga/Pga (top) and Otof ${ }^{-1-}$ (bottom) mice. (h) Pooled amplitude distributions for monophasic EPSCs of all Otof ${ }^{+/+}$and Otof Pga/Pga boutons ( $n=6$ cells and 577 EPSCs, and $n=4$ cells and 235 EPSCs, respectively). Bin width in the histogram is $5 \mathrm{pA}$. (i) There was no significant difference in average EPSC size for the two genotypes in the cumulative amplitude distributions $(P=0.14)$.

mice showed fast rise without obvious steps (Fig. 4d,e). Large EPSCs with kinetics identical to small EPSCs have been proposed to reflect highly synchronized multivesicular release ${ }^{32}$. The amplitude distribution of monophasic EPSCs was not significantly different in Otof $\mathrm{Pga} / \mathrm{Pga}$ SGNs as compared to controls (Kolmogorov-Smirnov test, $P=0.14$; Fig. 4h,i). Moreover, we detected action potential generation by recording action currents in the loose-patch configuration (Fig. $\mathbf{4 g}$ ). Together, these results suggest that Otof ${ }^{\mathrm{Pga} / \mathrm{Pga}}$ synapses should be capable of encoding sound into spiking activity in auditory nerve fibers, albeit at lower rates than wild-type synapses.

We recorded from SGNs of Otof ${ }^{-1-}$ mice of the same age and observed variably sized EPSCs at a very low rate ( $n=5 \mathrm{Otof}^{-/-} \mathrm{SGNs}$; Fig. 4c), indicating that the observed $\Delta C_{\mathrm{m}}$ in Otof $^{-1-}$ IHCs (ref. 23 and Fig. 2) did indeed report synaptic transmitter release. We also observed action currents in the loose-patch configuration (Fig. $\mathbf{4 g}$ ). In conclusion, transmitter release and postsynaptic spike generation in SGNs occur in otoferlin mutants and EPSC variability was also observed in the absence of otoferlin.

\section{Systems consequences of impaired vesicle replenishment}

How can the partial defect at the ribbon synapse that we found in vitro lead to such severe hearing impairment? We reasoned that spontaneous transmitter release in the absence of sound could steadily deplete the RRP in Otof ${ }^{P g a / P g a} \mathrm{IHCs}$ as a result of impaired vesicle supply. To test this hypothesis, we performed extracellular recordings with microelectrodes targeted to the cochlear nucleus and the auditory nerve ${ }^{34,35}$. Sound-driven single-neuron activity was scarce and only found at high stimulus intensities ( $>100 \mathrm{~dB}$ at $10 \mathrm{~Hz}$ ). Broadband stimulation (whitenoise bursts) of sound-responsive neurons in Otof ${ }^{\mathrm{Pga} / \mathrm{Pga}}$ mice revealed very low sound-driven spike rates, lacking the peak at sound onset typically observed in $\mathrm{Otof}^{+/+}$auditory nerve fibers and bushy cells (Fig. 5a).
Sound-responsive neurons in Otof ${ }^{P g a / P g a}$ mice, unlike in $\mathrm{Otof}^{+/+}$mice, could not be further classified into auditory nerve fibers and cochlear nucleus neurons on the basis of their response properties ${ }^{34}$. Thus, we used data from putative auditory nerve fibers and bushy cells from Otof $^{+/+}$mice as controls.

Lowering stimulus rates $(<10 \mathrm{~Hz})$ gradually improved sound onset responses (Fig. 5b and Supplementary Fig. 3) and thresholds (Supplementary Fig. 3) in Otof ${ }^{P g a / P g a}$ neurons. We favor the interpretation that, at lower stimulus rates, vesicle supply can also build up a standing RRP at Otof ${ }^{P g a / P g a}$ IHC synapses. In addition, there was a notable depression in the number of spikes occurring during the first trials of stimulation, especially at high stimulus rates, in Otof $\mathrm{Pga} / \mathrm{Pga}$ neurons (Fig. 5c), whereas such an adaptation was only seen at $10 \mathrm{~Hz}$ in $\mathrm{Otof}^{+/+}$neurons. Moreover, even at a rate of $1 \mathrm{~Hz}, 12 \%$ of the stimulus presentations failed to evoke spikes in Otof ${ }^{\mathrm{Pga} / \mathrm{Pga}}$ neurons, whereas $\mathrm{Otof}^{+/+}$neurons always responded. Finally, Otof ${ }^{\mathrm{Pga} / \mathrm{Pga}}$ neurons had strongly increased latencies and jitter of the first spike for all interstimulus intervals (Fig. 5d). In summary, spiking at sound onset occurred with low reliability and high temporal jitter in Otof ${ }^{P g a / P g a}$ neurons, and probably did not allow summation into a sizable auditory population response ${ }^{36}$, thereby explaining the absence of auditory evoked potentials (Fig. 1), even for increased interstimulus intervals (up to $4 \mathrm{~s}$, data not shown). The distribution of spontaneous spike rates in Otof ${ }^{P g a / P g a}$ neurons (mean rate, $4.7 \pm 1.0 \mathrm{~Hz}$ ) differed from that in $\mathrm{Otof}^{+/+}$auditory nerve fibers and cochlear nucleus units $(23.9 \pm 2.7 \mathrm{~Hz})$ in that all units had spontaneous rates below $30 \mathrm{~Hz}$ (Supplementary Fig. 3). Irrespective of whether sound-responsive neurons in $\mathrm{Otof}{ }^{\mathrm{Pga} / \mathrm{Pga}}$ mice represent auditory nerve fibers or principal neurons of the cochlear nucleus, these in vivo data support the hypothesis that auditory fatigue is the result of defective vesicle replenishment at the IHC synapses in Otof ${ }^{\mathrm{Pga} / \mathrm{Pga}}$ mice. 

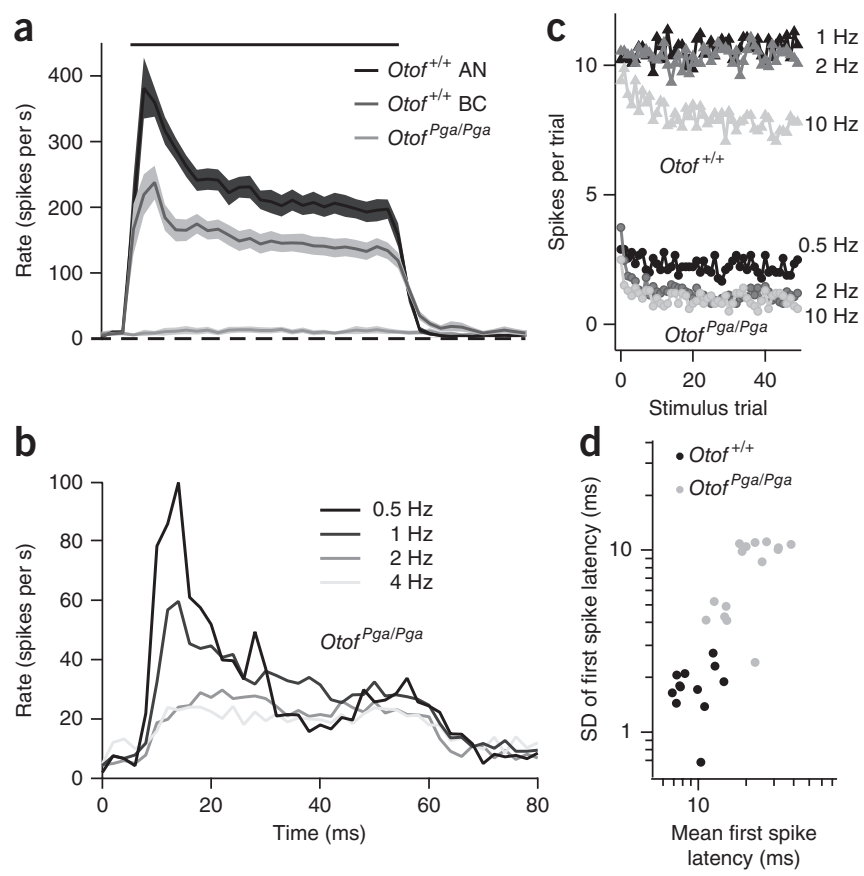

\section{Reduced otoferlin protein levels in Otof Pga/Pga IHCs}

We next addressed potential molecular mechanisms by which the pachanga mutation could affect the function of otoferlin in vesicle priming. We first examined the expression of Otof mRNA and protein. Otof mRNA levels were not significantly altered in Otof Pga/Pga mice, as assessed by real-time PCR $\left(1.6 \pm 0.2\right.$-fold of $\mathrm{Otof}^{+/+}, n=4$, $P=0.11)$. Localization and protein levels of otoferlin were studied by semi-quantitative optical microscopy of immunolabeled IHCs. We found overlapping distributions of Vglut3 (glutamate transporter of IHC synaptic vesicles ${ }^{37-39}$ ) and otoferlin immunofluorescence throughout the cytosol and along the plasma membrane in both Otof ${ }^{+/+}$and Otof ${ }^{P a / P g a}$ IHCs. The latter, however, showed much weaker otoferlin immunofluorescence (Fig. 6). We quantified otoferlin protein levels using antibodies to $\mathrm{N}$ - and C-terminal epitopes; binding of either of the antibodies was unlikely to be affected by the point mutation in the $\mathrm{C}_{2} \mathrm{~F}$ domain. In basolateral and apical IHC compartments, otoferlin protein levels were highest in $\mathrm{Otof}^{+/+}$

Figure 6 The pachanga mutation causes a reduction in otoferlin protein levels and a change in secondary structure. (a-f) Projected confocal sections of apical cochlear turns of different genotypes following immunolabeling for otoferlin ( $\mathrm{N}$ terminal, green) and Vglut3 (shown only in a, red) processed under identical conditions. ap, apical; bas, basolateral; nuc, nucleus. Scale bar represents $5 \mu \mathrm{m}$. (g) Fluorescence intensity averaged over an apical and a basal cytosolic region in either channel for the different genotypes. (h,i) Circular dichroism spectroscopy of purified wild-type and pachanga $\mathrm{C}_{2} \mathrm{~F}$ domains, averaged traces ( \pm s.e.m.) in the presence of EDTA (h) and sample traces in the presence of EDTA or $\mathrm{Ca}^{2+}$ (i). (j) Tryptophane autofluorescence of purified wild-type $\mathrm{C}_{2} \mathrm{~F}$ domain, single traces in the presence of EDTA, $\mathrm{Ca}^{2+}$ and $\mathrm{Mg}^{2+}$. (k) Proposed functions of otoferlin in hair cell exocytosis. We propose that there is a defect in priming in OtofPga/Pga mice, but docking, stabilization of a normal RRP (under release-inhibiting conditions), $\mathrm{Ca}^{2+}$-triggered fusion, EPSC and spike generation, and endocytic membrane retrieval seem to function normally in Otof Pga/Pga IHCs. If, however, consumption as a result of spontaneous and evoked release is as high as in vivo, a standing RRP cannot be maintained in Otof Pga/Pga IHCs (gray ellipse versus black ellipse). Previous work ${ }^{23}$ and these results suggest that otoferlin and $\mathrm{Ca}^{2+}$ act on both vesicle priming and fusion.
Figure 5 Reduced and fatiguing sound encoding in Otof Pga/Pga mice. (a) Mean poststimulus time histograms ( \pm s.e.m.) of auditory nerve fibers (AN, $n=15$, primary-like discharge pattern, depth $>1,000 \mu \mathrm{m}$ from the surface of the cochlear nucleus) and bushy cells (BC, $n=34$, primary-like type response with a depth of $<1,000 \mu \mathrm{m}$ or primary-like response with notch discharge pattern) obtained from responses to $10-\mathrm{Hz}$ tone bursts at a characteristic frequency $30 \mathrm{~dB}$ above threshold in $\mathrm{Otof}^{+/+}$mice and sound-responsive neurons recorded from the region of the cochlear nucleus in OtofPgalPga mice ( $n=10,10-\mathrm{Hz}$ noise bursts at $120-140 \mathrm{~dB}$ $\mathrm{SPL}$ ). (b) Poststimulus time histograms of Otof Pga/Pga units stimulated at different rates $(0.5-4 \mathrm{~Hz}, n=8-13)$. (c) The number of sound-evoked spikes during the first 50 trials of stimulation in Otof Pga/Pga $(n=15)$ and $\operatorname{Otof}^{+/+}(n=15)$ units. (d) Mean and s.d. of first spike latency in Otof Pga/Pga $(n=14)$ and $\mathrm{Otof}^{+/+}(n=12)$ units.

mice, followed by Otof ${ }^{+/-}$, Otof $f^{P g a / P g a}$ and then Otof Pga/- mice (Fig. 6b-e,g). Otof ${ }^{-/}$mice (Fig. 6f,g) served as negative controls. Vglut3 immunofluorescence was decreased by approximately $30 \%$ in all mutant phenotypes, indicating that the reduction in otoferlin immunofluorescence may be partially attributable to a reduction in synaptic vesicle number in these IHCs (Fig. 6g). Nonetheless, the reduced relative fluorescence (otoferlin/Vglut3) indicates that synaptic vesicles in Otof ${ }^{\mathrm{Pga} /-}$ and Otof ${ }^{\mathrm{Pga} / \mathrm{Pga}}$ IHCs contain fewer copies of otoferlin. In addition, otoferlin immunofluorescence in Otof ${ }^{P g a / P g a}$ IHCs was reduced more strongly at the plasma membrane than in the cytoplasm (Supplementary Fig. 4).

We then examined the effect of the pachanga point mutation on the secondary structure of the otoferlin $\mathrm{C}_{2} \mathrm{~F}$ domain by circular dichroism spectroscopy. We observed slight changes in the circular dichroism spectrum, suggesting that there are minor structural differences between the wild-type and the mutated $\mathrm{C}_{2} \mathrm{~F}$ domains (Fig. 6h). Adding $\mathrm{Ca}^{2+}$ to the protein solution had no effect on the circular dichroism spectra of wild-type and mutated $\mathrm{C}_{2} \mathrm{~F}$ domains (Fig. 6i) or on tryptophane autofluorescence of the wild-type $\mathrm{C}_{2} \mathrm{~F}$
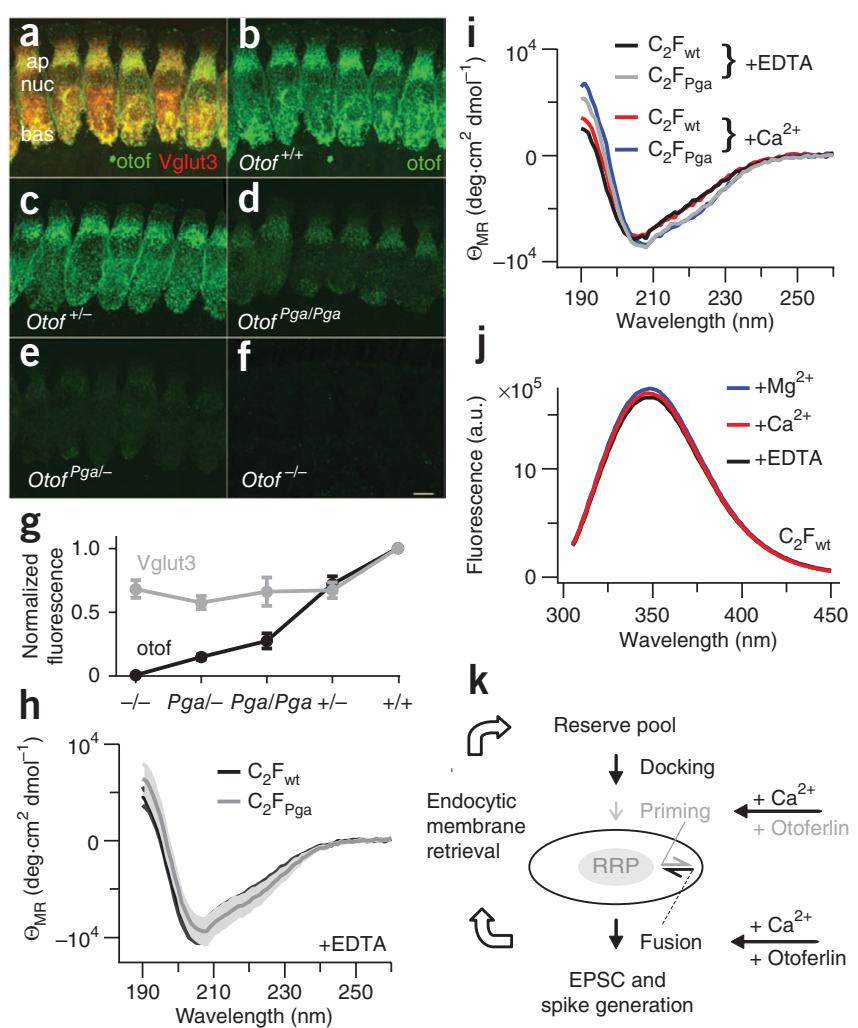
domain (Fig. 6j), indicating a lack of $\mathrm{Ca}^{2+}$ binding. Moreover, we did not observe $\mathrm{Ca}^{2+}$-dependent phospholipid binding (Supplementary Fig. 4) for either the wild-type or the mutated $\mathrm{C}_{2} \mathrm{~F}$ domain. We concluded that lower protein levels of otoferlin, potentially together with minor structural changes and impairment of protein-protein interactions, but not alteration of $\mathrm{Ca}^{2+}$ or phospholipid binding, contribute to the auditory phenotype of Otof ${ }^{P g a / P g a}$ mice. Potential mechanisms for the lower otoferlin protein levels in Otof ${ }^{P g a / P g a} \mathrm{IHC}$ include a higher incidence of misfolding during protein synthesis, leading to direct degradation, and decreased protein stability, resulting in faster degradation.

\section{DISCUSSION}

The IHC ribbon synapse outperforms other synapses with respect to synaptic vesicle replenishment capacity. We characterized, to the best of our knowledge, the first known mutation that selectively affects this process in IHCs and identified otoferlin as a component of the underlying molecular machinery. The mutation impairs vesicle replenishment most likely by reducing otoferlin protein levels and potentially by interfering with protein-protein interactions. Our analysis of Otof ${ }^{P g a / P g a}$ IHC synapses indicates that compromised vesicle replenishment leads to auditory fatigue and profound hearing impairment, as a sufficiently large standing RRP cannot be maintained during synaptic activity in vivo.

We took advantage of the maintenance of $\mathrm{Ca}^{2+}$ influx-triggered fusion of readily releasable vesicles in the Otof ${ }^{P g a / P g a}$ mutant $^{26}$. Our results provide evidence for an additional function of otoferlin in vesicle priming (Fig. 6k) and argue against potential defects in vesicle trafficking and docking, synaptic $\mathrm{Ca}^{2+}$ signaling, fusion and transmitter release, and endocytic membrane retrieval in Otof ${ }^{P g a / P g a}$ IHCs. Currently we cannot exclude an impairment of active zone clearance after synaptic fusion ${ }^{40}$, as that would be functionally indistinguishable. It is possible, although less likely, that the reduced sustained exocytosis and smaller fast flash response result from a major contribution of a slowly releasable pool of vesicles (docked at greater distance to $\mathrm{Ca}^{2+}$ channels ${ }^{41}$ or using a different $\mathrm{Ca}^{2+}$ sensor ${ }^{42}$ ) to sustained exocytosis and from selectively impaired exocytosis of those slowly releasable vesicles in Otof ${ }^{\mathrm{Pga} / \mathrm{Pga}}$ IHCs.

On the basis of our in vitro recordings, we conclude that a normal standing RRP can be established in Otof ${ }^{P g a / P g a}$ IHCs as long as enough time is provided for vesicle replenishment. Most likely, a normal number of 'slots' (close to $\mathrm{Ca}^{2+}$ channels ${ }^{27,43}$ ) are available for releasable vesicles, which provide an intact $\mathrm{Ca}^{2+}$ influx-exocytosis coupling, as indicated by normal RRP release kinetics. We favor the hypothesis that, in vivo, ongoing exocytosis in the absence of sound stimulation leads to steady vesicle consumption and thus a smaller standing RRP in Otof ${ }^{P g a / P g a}$ IHCs. This reduced RRP and the slower speed of vesicle supply probably limit the rates of transmitter release and subsequent neuronal spiking on sound stimulation.

In addition to accelerating vesicle replenishment, otoferlin has been implicated in $\mathrm{Ca}^{2+}$-triggered fusion ${ }^{23}$. Does otoferlin then assume multiple functions in IHC exocytosis? In the absence of otoferlin, a stronger impairment in vesicle replenishment than that observed in Otof ${ }^{P g a / P g a}$ IHCs could arise. However, the complete lack of fast exocytosis even after long periods of rest and the partially preserved slow exocytosis in Otof $^{-/-}$IHCs cannot simply be explained this way and instead indicates an additional requirement for otoferlin in fusion $^{23}$ (Fig. 6k). Although the perturbation of vesicle replenishment and fusion causes a complete loss of fast exocytosis in $\mathrm{Otof}^{-/-}$IHCs, the functionality of the pachanga mutant protein and the number of protein copies present on synaptic vesicles apparently suffice to support fast fusion in Otof ${ }^{\mathrm{Pga} / \mathrm{Pga}}$ IHCs, but fail to maintain efficient vesicle replenishment. Regarding this dual-function hypothesis for otoferlin, it is noteworthy that a function upstream of fusion was recently also reported for synaptotagmin 1 (ref. 44).

Otoferlin, which seems to be absent from other synapses such as retinal ribbon synapses ${ }^{35}$, is an attractive candidate for conferring the fast vesicle replenishment capacity to IHCs. During strong in vitro stimulation, IHCs sustain a near constant exocytosis rate of hundreds (700 in this study) of vesicles per s per active zone or tens of vesicles per s per 'RRP slot' for at least $1 \mathrm{~s}$ during ongoing stimulation. The vesicle supply rates of wild-type IHCs exceed those of rat retinal bipolar cells by almost an order of magnitude (70 vesicles per s per active zone), despite comparable synaptic ultrastructure and RRP size of bipolar cell active zones ${ }^{14}$. Estimates of maximal vesicle supply in retinal photoreceptors of the salamander, which have larger active zones than IHCs and bipolar cells ${ }^{45}$, amount to approximately 200 vesicles per s per active zone ${ }^{13,15}$. Notably, sustained exocytosis of mouse vestibular hair cells operates at lower rates than in cochlear IHCs and is reduced on deletion of otoferlin ${ }^{46}$. Different rates of vesicle supply and different effects of otoferlin deletion in auditory and vestibular hair cells might reflect the involvement of distinct proteins that co-determine the replenishment rate. Unlike retinal and vestibular junctions, each postsynaptic auditory neuron is driven by a single IHC active zone and fires up to hundreds of hertz during ongoing acoustic stimulation (for review, see ref. 2), requiring similar or higher rates of release.

How can one reconcile the substantial sustained exocytosis $(200$ vesicles per s per active zone) observed in IHCs of Otof ${ }^{P g a / P g a}$ mice in vitro with the severe impairment of sound encoding in vivo? If other aspects of cochlear function apart from vesicle replenishment are intact, as indicated by normal otoacoustic emissions, cochlear microphonics and summating potentials, then why were high sound pressure levels required to elicit neuronal responses? Although alternative interpretations cannot be ruled out at present, we favor the hypothesis that the requirement for otoferlin may be most critical for maintaining a standing RRP during weak stimulation. The $\mathrm{Ca}^{2+}$ signal elicited by strong stimulation, saturating depolarizations and elevated $\left[\mathrm{Ca}^{2+}\right]_{\mathrm{e}}$ (Fig. 2), high $\left[\mathrm{K}^{+}\right]_{\mathrm{e}}$ (Figs. 3 and 4), and high sound intensities (Fig. 5), might have been high enough to enhance vesicle supply and support substantial transmission even in Otof Pga/Pga mice. It is tempting to speculate that the multi- $\mathrm{C}_{2}$ domain protein otoferlin endows vesicle supply at the IHC synapse with high $\mathrm{Ca}^{2+}$ sensitivity to enable sufficient vesicle replenishment during weak stimulation. Future studies are required to further characterize the $\mathrm{Ca}^{2+}$ dependence of vesicle supply in IHCs.

\section{METHODS}

Methods and any associated references are available in the online version of the paper at http://www.nature.com/natureneuroscience/.

Note: Supplementary information is available on the Nature Neuroscience website.

\section{ACKNOWLEDGMENTS}

We would like to thank E. Glowatzki and D. Khimich for teaching us the postsynaptic patch clamp, K. Tittman, D. Fasshauer and R. Jahn for advice and support for protein biochemistry, C.P. Richter and M.A. Cheatham for advice on the electrocochleography, A. Leonov and C. Griesinger for the DM-nitrophen, P. Jonas for the parvalbumin taqman probe, members of the InnerEarLab for discussion, M. Rutherford, J. Singer, E. Neher, J. Siegel, P. Heil, T. Sakaba, R. Nouvian, A. Lysakowski and A. Lee for comments on the manuscript and C. Rüdiger, S. Blume, N. Dankenbrink-Werder and M. Köppler for expert technical assistance. This work was supported by a fellowship of the Alexander von Humboldt Foundation to T.P., a fellowship of the Boehringer Ingelheim Fonds to K.R., a fellowship of MED-EL company to H.T., grants from the German Research 
Foundation (Center for Molecular Physiology of the Brain, T.M. and N.B.; Fellowship to N.S.), the European Commission (Eurohear, T.M.), the Max-PlanckSociety (Tandemproject, T.M. and N.B.), the German Ministry for Education and Science via the Bernstein Focus Neurotechnology Goettingen (grant no. 01GQ0810 to T.M.), the State of Lower Saxony ('VW-Vorab' to T.M. and Christoph Matthias), and the US National Institutes of Health (DC007704, U.M.)

\section{AUTHOR CONTRIBUTIONS}

The study was designed by T.M., T.P., U.M., N.S., E.R. and N.B. T.P. carried out the IHC patch clamp and flash photolysis, extracellular postsynaptic recordings and immunohistochemistry and contributed to the electron microscopy. L.L. performed in vivo single-unit recordings, electrocochleography and auditory brainstem responses. K.R. carried out real-time PCR, protein purification, circular dichroism spectroscopy, fluorimetry and the floatation assay. H.T. performed postsynaptic recordings. M.S. carried out the ENU screen and initial auditory testing. D.R. performed electron microscopy. T.F. carried out $\mathrm{Ca}^{2+}$ imaging. N.S. performed in vivo physiology. E.R. generated the knockout mice. J.S.B. and L.M.T. started the ENU screen. T.M. and T.P. prepared the manuscript.

\section{COMPETING FINANCIAL INTERESTS}

The authors declare no competing financial interests.

Published online at http://www.nature.com/natureneuroscience/.

Reprints and permissions information is available online at http://www.nature.com/ reprintsandpermissions/.

1. Kiang, N.Y.-S., Watanabe, T., Thomas, E.C. \& Clark, L.F. Discharge Pattern of Single Fibers in the Cat's Auditory Nerve (MIT Press, Cambridge, Massachusetts, 1965)

2. Geisler, C.D. From Sound to Synapse (Oxford University Press, New York, 1998).

3. Parsons, T.D., Lenzi, D., Almers, W. \& Roberts, W.M. Calcium-triggered exocytosis and endocytosis in an isolated presynaptic cell: capacitance measurements in saccular hair cells. Neuron 13, 875-883 (1994).

4. Moser, T. \& Beutner, D. Kinetics of exocytosis and endocytosis at the cochlear inner hair cell afferent synapse of the mouse. Proc. Natl. Acad. Sci. USA 97, 883-888 (2000).

5. Schnee, M.E., Lawton, D.M., Furness, D.N., Benke, T.A. \& Ricci, A.J. Auditory hair cell-afferent fiber synapses are specialized to operate at their best frequencies. Neuron 47, 243-254 (2005).

6. Griesinger, C.B., Richards, C.D. \& Ashmore, J.F. Fast vesicle replenishment allows indefatigable signaling at the first auditory synapse. Nature 435, 212-215 (2005)

7. Keen, E.C. \& Hudspeth, A.J. Transfer characteristics of the hair cell's afferent synapse. Proc. Natl. Acad. Sci. USA 103, 5537-5542 (2006).

8. Goutman, J.D. \& Glowatzki, E. Time course and calcium dependence of transmitter release at a single ribbon synapse. Proc. Natl. Acad. Sci. USA 104, 16341-16346 (2007).

9. von Gersdorff, H. \& Matthews, G. Depletion and replenishment of vesicle pools at a ribbon-type synaptic terminal. J. Neurosci. 17, 1919-1927 (1997).

10. Gomis, A., Burrone, J. \& Lagnado, L. Two actions of calcium regulate the supply of releasable vesicles at the ribbon synapse of retinal bipolar cells. J. Neurosci. 19, 6309-6317 (1999).

11. Zenisek, D., Steyer, J.A. \& Almers, W. Transport, capture and exocytosis of single synaptic vesicles at active zones. Nature 406, 849-854 (2000).

12. Thoreson, W.B., Rabl, K., Townes-Anderson, E. \& Heidelberger, R. A highly $\mathrm{Ca}^{2+}$ sensitive pool of vesicles contributes to linearity at the rod photoreceptor ribbon synapse. Neuron 42, 595-605 (2004).

13. Rabl, K., Cadetti, L. \& Thoreson, W.B. Kinetics of exocytosis is faster in cones than in rods. J. Neurosci. 25, 4633-4640 (2005).

14. Singer, J.H. \& Diamond, J.S. Vesicle depletion and synaptic depression at a mammalian ribbon synapse. J. Neurophysiol. 95, 3191-3198 (2006).

15. Jackman, S.L. et al. Role of the synaptic ribbon in transmitting the cone light response. Nat. Neurosci. 12, 303-310 (2009).

16. Hosoi, N., Sakaba, T. \& Neher, E. Quantitative analysis of calcium-dependent vesicle recruitment and its functional role at the calyx of Held synapse. J. Neurosci. 27, 14286-14298 (2007).

17. Saviane, C. \& Silver, R.A. Fast vesicle reloading and a large pool sustain high bandwidth transmission at a central synapse. Nature 439, 983-987 (2006).

18. Khimich, D. et al. Hair cell synaptic ribbons are essential for synchronous auditory signaling. Nature 434, 889-894 (2005).
19. Moser, T., Neef, A. \& Khimich, D. Mechanisms underlying the temporal precision of sound coding at the inner hair cell ribbon synapse. J. Physiol. (Lond.) 576, 55-62 (2006)

20. Wittig, J.H. Jr. \& Parsons, T.D. Synaptic ribbon enables temporal precision of hair cell afferent synapse by increasing the number of readily releasable vesicles: a modeling study. J. Neurophysiol. 100, 1724-1739 (2008).

21. Eisen, M.D., Spassova, M. \& Parsons, T.D. Large releasable pool of synaptic vesicles in chick cochlear hair cells. J. Neurophysiol. 91, 2422-2428 (2004).

22. Johnson, S.L., Marcotti, W. \& Kros, C.J. Increase in efficiency and reduction in $\mathrm{Ca}^{2+}$ dependence of exocytosis during development of mouse inner hair cells. J. Physiol. (Lond.) 563, 177-191 (2005).

23. Roux, I. et al. Otoferlin, defective in a human deafness form, is essential for exocytosis at the auditory ribbon synapse. Cell 127, 277-289 (2006).

24. Roux, I. et al. Myosin VI is required for the proper maturation and function of inner hair cell ribbon synapses. Hum. Mol. Genet. 18, 4615-4628 (2009).

25. Heidrych, P. et al. Otoferlin interacts with myosin VI: implications for maintenance of the basolateral synaptic structure of the inner hair cell. Hum. Mol. Genet. 18 2779-2790 (2009).

26. Schwander, M. et al. A forward genetics screen in mice identifies recessive deafness traits and reveals that pejvakin is essential for outer hair cell function. $J$. Neurosci. 27, 2163-2175 (2007)

27. Brandt, A., Khimich, D. \& Moser, T. Few CaV1.3 channels regulate the exocytosis of a synaptic vesicle at the hair cell ribbon synapse. J. Neurosci. 25, 11577-11585 (2005).

28. Frank, T., Khimich, D., Neef, A. \& Moser, T. Mechanisms contributing to synaptic $\mathrm{Ca}^{2+}$ signals and their heterogeneity in hair cells. Proc. Natl. Acad. Sci. USA 106 4483-4488 (2009)

29. Spassova, M.A. et al. Evidence that rapid vesicle replenishment of the synaptic ribbon mediates recovery from short-term adaptation at the hair cell afferent synapse. J. Assoc. Res. Otolaryngol. 5, 376-390 (2004).

30. Meyer, A.C. et al. Tuning of synapse number, structure and function in the cochlea. Nat. Neurosci. 12, 444-453 (2009)

31. Li, G.L., Keen, E., Andor-Ardo, D., Hudspeth, A.J. \& von Gersdorff, H. The unitary event underlying multiquantal EPSCs at a hair cell's ribbon synapse. J. Neurosci. 29, 7558-7568 (2009).

32. Glowatzki, E. \& Fuchs, P.A. Transmitter release at the hair cell ribbon synapse. Nat. Neurosci. 5, 147-154 (2002).

33. Grant, L., Yi, E. \& Glowatzki, E. Two modes of release shape the postsynaptic response at the inner hair cell ribbon synapse. J. Neurosci. 30, 4210-4220 (2010).

34. Taberner, A.M. \& Liberman, M.C. Response properties of single auditory nerve fibers in the mouse. J. Neurophysiol. 93, 557-569 (2005).

35. Strenzke, N. et al. Complexin-I is required for high-fidelity transmission at the endbulb of held auditory synapse. J. Neurosci. 29, 7991-8004 (2009).

36. Starr, A., Michalewski, H.J., Feng, G. \& Moser, T. Perspectives on auditory neuropathy: disorders of inner hair cell, auditory nerve and their synapse. in The Senses: a Comprehensive Reference (eds. Dallos, P. \& Oertel, D.) 397-412 (Elsevier, Amsterdam, 2008).

37. Obholzer, N. et al. Vesicular glutamate transporter 3 is required for synaptic transmission in zebrafish hair cells. J. Neurosci. 28, 2110-2118 (2008).

38. Seal, R.P. et al. Sensorineural deafness and seizures in mice lacking vesicular glutamate transporter 3. Neuron 57, 263-275 (2008).

39. Ruel, J. et al. Impairment of SLC17A8 encoding vesicular glutamate transporter-3, VGLUT3, underlies nonsyndromic deafness DFNA25 and inner hair cell dysfunction in null mice. Am. J. Hum. Genet. 83, 278-292 (2008).

40. Hosoi, N., Holt, M. \& Sakaba, T. Calcium dependence of exo- and endocytotic coupling at a glutamatergic synapse. Neuron 63, 216-229 (2009).

41. Wadel, K., Neher, E. \& Sakaba, T. The coupling between synaptic vesicles and $\mathrm{Ca}^{2+}$ channels determines fast neurotransmitter release. Neuron 53, 563-575 (2007).

42. Wölfel, M., Lou, X. \& Schneggenburger, R. A mechanism intrinsic to the vesicle fusion machinery determines fast and slow transmitter release at a large CNS synapse. J. Neurosci. 27, 3198-3210 (2007).

43. Neef, J. et al. The $\mathrm{Ca}^{2+}$ channel subunit beta2 regulates $\mathrm{Ca}^{2+}$ channel abundance and function in inner hair cells and is required for hearing. J. Neurosci. 29, 10730-10740 (2009)

44. de Wit, H. et al. Synaptotagmin-1 docks secretory vesicles to syntaxin-1/SNAP-25 acceptor complexes. Cell 138, 935-946 (2009).

45. Sterling, P. \& Matthews, G. Structure and function of ribbon synapses. Trends Neurosci. 28, 20-29 (2005).

46. Dulon, D., Safieddine, S., Jones, S.M. \& Petit, C. Otoferlin is critical for a highly sensitive and linear calcium-dependent exocytosis at vestibular hair cell ribbon synapses. J. Neurosci. 29, 10474-10487 (2009).

47. Neef, A. et al. Probing the mechanism of exocytosis at the hair cell ribbon synapse. J. Neurosci. 27, 12933-12944 (2007).

48. Beutner, D., Voets, T., Neher, E. \& Moser, T. Calcium dependence of exocytosis and endocytosis at the cochlear inner hair cell afferent synapse. Neuron 29 681-690 (2001) 


\section{ONLINE METHODS}

Animals. Mice aged 1 (postsynaptic patch clamp), 2-3 (presynaptic patch clamp and immunohistochemistry, auditory brainstem responses) and $3-5$ weeks (in vivo auditory physiology) were used. The generation of $\mathrm{Otof}^{-1}$ mice will be described elsewhere (E.R., Bresee, C., Neef, J., Nair, R., Bulankina, A., K.R., Koch, M., N.B., Rhee, J.S., Kügler, S., Brigande, J. and T.M., unpublished observations). Generation of Otof ${ }^{P g a / P g a}$ mice was described previously ${ }^{26}$. C57BL/6 mice were used as control animals. Animal handling and experiments complied with national animal care guidelines and were approved by the University of Goettingen Board for Animal Welfare and the Animal Welfare Office of the state of Lower Saxony.

Patch-clamp recordings. IHCs from the apical coils of freshly dissected organs of Corti were patch clamped in the perforated-patch (depolarizations) or wholecell (flash photolysis, $\mathrm{Ca}^{2+}$ imaging) configuration as described previously $y^{4,48}$. The pipette solutions for perforated-patch experiments contained $130 \mathrm{mM}$ cesium gluconate, $10 \mathrm{mM}$ tetraethylammonium-chloride (TEA-Cl), $10 \mathrm{mM} 4$-aminopyridine (Merck), $1 \mathrm{mM} \mathrm{MgCl}, 10 \mathrm{mM}$ cesium HEPES (pH 7.17) and $300 \mu \mathrm{g} \mathrm{ml}^{-1}$ amphotericin $\mathrm{B}$ (Calbiochem). The pipette solution for flash photolysis contained $120 \mathrm{mM}$ cesium gluconate, $20 \mathrm{mM}$ TEA-Cl, $20 \mathrm{mM}$ cesium HEPES ( $\mathrm{pH}$ 7.2), $0.3 \mathrm{mM}$ mag-fura-2 (Invitrogen), $10 \mathrm{mM} \mathrm{DM}$-nitrophen (gift of A. Leonov and C. Griesinger, Göttingen), $5 \mathrm{mM}$ 1,3-diaminopropan-2-ol-tetraacetic acid and $10 \mathrm{mM}$ $\mathrm{CaCl}_{2}$. The pipette solution for $\mathrm{Ca}^{2+}$ imaging contained $126 \mathrm{mM}$ cesium glutamate, $13 \mathrm{mM}$ TEA-Cl, $20 \mathrm{mM}$ cesium HEPES, $1 \mathrm{mM} \mathrm{MgCl}_{2}, 0.1 \mathrm{mMCaCl}_{2}, 2 \mathrm{mMMgATP}$, $0.3 \mathrm{mM}$ NaGTP, $2 \mathrm{mM}$ EGTA and $0.4 \mathrm{mM}$ Fluo- $5 \mathrm{~N}$ (Penta- $\mathrm{K}^{+}$salt, Invitrogen), $\mathrm{pH}$ 7.0. The extracellular solutions contained $113 \mathrm{mM} \mathrm{NaCl}\left(102 \mathrm{mM}\right.$ for $\mathrm{Ca}^{2+}$ imaging), $35 \mathrm{mM}$ TEA-Cl, $2.8 \mathrm{mM} \mathrm{KCl}, 2 \mathrm{mM} \mathrm{CaCl}_{2}$ (10 mM for flash-photolysis and some perforated-patch experiments, $5 \mathrm{mM}$ for $\mathrm{Ca}^{2+}$ imaging), $1 \mathrm{mM} \mathrm{MgCl}_{2}$, $10 \mathrm{mM}$ sodium HEPES, $1 \mathrm{mM} \mathrm{CsCl}$ and $11.1 \mathrm{mM}$ D-glucose ( $\mathrm{pH}$ 7.2).

Loose-patch and whole-cell recordings from postsynaptic boutons were performed as described previously ${ }^{32}$ using pipettes with small tip-opening (8-15 M $\Omega$ following pressure polishing ${ }^{49}$ ), a pipette solution containing $150 \mathrm{mM} \mathrm{KCl}$, $3.5 \mathrm{mM} \mathrm{MgCl}_{2}, 0.1 \mathrm{mM} \mathrm{CaCl}_{2}, 5 \mathrm{mM}$ EGTA, $5 \mathrm{mM}$ potassium HEPES and $2.5 \mathrm{mM}$ $\mathrm{Na}_{2} \mathrm{ATP}$ (pH 7.2) and an extracellular solution containing $5.8 \mathrm{mM} \mathrm{KCl}, 155 \mathrm{mM}$ $\mathrm{NaCl}, 0.9 \mathrm{mM} \mathrm{MgCl}_{2}, 1.3 \mathrm{mM} \mathrm{CaCl}_{2}, 0.7 \mathrm{mM} \mathrm{NaH}_{2} \mathrm{PO}_{4}, 5.6 \mathrm{mM}$ D-glucose, $10 \mathrm{mM}$ sodium HEPES ( $\mathrm{pH}$ 7.4). In most recordings, tetrodotoxin $(1-2 \mu \mathrm{M})$ was added to block voltage-gated sodium channels. All chemicals were obtained from Sigma-Aldrich, unless stated otherwise. EPC-9 or EPC-10 amplifiers (HEKA Electronics), controlled by Pulse or Patchmaster software, were used to sample and filter currents at 20 and $5 \mathrm{kHz}$, respectively. We measured $\Delta C_{\mathrm{m}}$ as previously described ${ }^{4}$ using depolarizations of different durations to peak $\mathrm{Ca}^{2+}$ current potential at intervals of $30-60 \mathrm{~s} . \Delta C_{\mathrm{m}}$ was estimated as the difference of the mean $C_{\mathrm{m}}$ after depolarization and the mean pre-pulse $C_{\mathrm{m}}$ (the initial $40 \mathrm{~ms}$ after the depolarization were skipped). Mean $\Delta C_{\mathrm{m}}$ and $\mathrm{Ca}^{2+}$ current estimates present grand averages calculated from the mean estimates of individual IHCs. In paired-pulse experiments, we used two 20 -ms-long pulses with variable interstimulus interval: 89, 154 and $504 \mathrm{~ms}$ and 30 s. Currents were leak corrected using a P/10-protocol. Recordings were performed at $21-23^{\circ} \mathrm{C}$. Flash photolysis was performed as described ${ }^{48}$.

Confocal imaging of $\mathrm{Ca}^{2+}$ signals at hair cell ribbon synapses. Confocal $\mathrm{Ca}^{2+}$ imaging was performed as previously described ${ }^{28} \cdot \mathrm{Ca}^{2+}$ microdomains were identified in $x y$ scans during 200-ms-long depolarizations and further characterized using spot detection (point scan mode of the confocal scanner). During spot detection measurements, the output of the photomultiplier tube (PMT) signal $(500 \mathrm{kHz})$ was temporally averaged to yield an effective sampling rate of $1.85 \mathrm{kHz}$. Isochronal spot detection measurements were made at the center of a $\mathrm{Ca}^{2+}$ microdomain and at the four directly neighboring pixels on each side of the center along each direction of the $x$ and $y$ axis (130-nm spacing between the neighboring recording locations and the center), each averaged five times. Only the maximum amplitude response was further analyzed. PMT dark current (measured with shutter closed) was subtracted for all measurements. Igor Pro (Wavemetrics) was used for analysis.

Recordings of cochlear potentials (electrocochleography), auditory brainstem responses and single-unit responses. Auditory brainstem response recordings were performed as described previously ${ }^{43}$. Clicks are presented in $\mathrm{dB}$ peak equivalent, and tone and noise bursts in $\mathrm{dB}$ sound pressure level.
For electrocochleography, the mouse head was fixed, the bulla was opened from a retroauricular incision, a silver ball-electrode was placed into the round window niche, and the difference potential to a subdermal needle at the vertex was amplified (50 times, custom-built amplifier) and sampled at a rate of $50 \mathrm{kHz}$ for $20 \mathrm{~ms}$. For analysis of CAP and summating potentials, responses to stimuli of inverting polarity were averaged and low-pass filtered $(3 \mathrm{kHz})$ offline using Matlab (Mathworks) software.

Single auditory neuron responses from the ventral cochlear nucleus and auditory nerve were performed essentially as described previously ${ }^{35}$. On audio-visual detection of spiking activity, units were further characterized by determining their spontaneous rate and responses to 50 -ms noise bursts presented at $0.5,1$, 2,4 or $10 \mathrm{~Hz}$. Attempts to record tuning curves did not yield consistent results in Otof $f^{P a / P g a}$ mice because of low spike rates that depended on interstimulus intervals, high thresholds (usually above $100 \mathrm{~dB}$ SPL) and broad frequency tuning. Subsequent offline spike detection using Matlab was based on amplitudes, waveform reproducibility and signal-to-noise ratio.

We assume that we recorded mainly from primary units of the cochlear nucleus because they were localized in the auditory nerve/cochlear nucleus region (many of them were too superficial to be auditory nerve fibers), the signal-to-noise ratio and our ability to achieve long recording durations were relatively good, better than in typical auditory nerve recordings, the responses to low-frequency sounds $(0.1-2 \mathrm{kHz})$ were not better than those to higher-frequency sounds, arguing against a vestibular origin, and the responses of individual units did not change after removal of whiskers, arguing against a trigeminal origin.

Spontaneous or sound-evoked responses also differed from wild-type olivocochlear efferents or vestibular neurons ${ }^{50}$. If we indeed recorded from such units, their responses must also have been affected by the mutation.

Immunostaining and confocal microscopy. Immunostaining was performed as previously described ${ }^{18}$. For primary antibodies, we used mouse IgG1 antibody to Ctbp2 (BD Biosciences, 1:200), rabbit antibody to GluR2/3 (Chemicon, 1:200), mouse antibody to calbindin (Swant, 1:500), mouse antibody to otoferlin (N terminal, Abcam, 1:500), rabbit antibody to otoferlin (C terminal, Synaptic Systems, 1:500) and rabbit antibody to Vglut3 (Synaptic Systems, 1:500). We used AlexaFluor 488- and AlexaFluor 568-labeled secondary antibodies (Invitrogen, 1:200). For three-dimensional reconstructions of the specimen, $z$ axis stacks of two-dimensional images were taken with a step size of $0.5 \mu \mathrm{m}$. They are shown in $z$ projections, created using ImageJ. Otoferlin and Vglut3 immunofluorescence signals were analyzed in apical and basolateral intracellular regions in maximum projections of confocal IHC sections. They were acquired at identical microscope settings and following parallel immunolabeling with the same procedure used for all genotypes.

Electron microscopy. The organs of Corti (apical cochlear coils) were explanted and exposed to stimulatory or inhibitory conditions for 10-15 min. For stimulation, they were incubated in a depolarizing saline (containing $50 \mathrm{mM} \mathrm{KCl}, 95 \mathrm{mM}$ $\mathrm{NaCl}, 1 \mathrm{mM} \mathrm{MgCl}_{2}, 5 \mathrm{mM} \mathrm{CaCl}_{2}, 10 \mathrm{mM}$ HEPES, $11.1 \mathrm{mM}$ D-glucose, $\mathrm{pH}$ 7.2, osmolarity approximately $300 \mathrm{mOsm}$ ) at $21-23^{\circ} \mathrm{C}$. For inhibition, the tissue was incubated in a Ca ${ }^{2+}$-free saline $\left(5 \mathrm{mM} \mathrm{KCl}, 140 \mathrm{mM} \mathrm{NaCl}, 3 \mathrm{mM} \mathrm{MgCl}_{2}, 5 \mathrm{mM}\right.$ EGTA, $10 \mathrm{mM}$ HEPES and $11.1 \mathrm{mM}$ D-glucose, pH 7.2, osmolarity approximately $300 \mathrm{mOsm}$ ) on ice. Thereafter, organs of Corti were incubated for 15-20 min in the respective solution supplemented with $4 \%$ glutaraldehyde (vol/vol, Electron Microscopy Sciences) at $21-23^{\circ} \mathrm{C}$. Afterwards, they were incubated overnight at $4{ }^{\circ} \mathrm{C}$ in $0.1 \mathrm{M}$ cacodylate buffer supplemented with $4 \%$ glutaraldehyde. After an additional fixation in $0.1 \% \mathrm{OsO}_{4}$ ( $\left.\mathrm{vol} / \mathrm{vol}\right)$, the samples were stained with $1 \%$ uranyl acetate ( $\mathrm{vol} / \mathrm{vol})$, and dehydrated in a series of ethanol washes and finally in propylene oxide. They were then embedded in Agar 100 (purchased through Science Services). Thin sections $(80 \mathrm{~nm}$ ) were counterstained with lead citrate and examined using a Philips CM 120 BioTwin transmission electron microscope. Pictures were taken with a TemCam F224A camera (TVIPS) at 20,000-fold magnification.

Quantitative image analysis was performed in iTEM software (Olympus), where we counted ribbon-associated synaptic vesicles (first row of vesicles around the ribbon with less than a vesicle diameter distance from the ribbon surface), membrane-proximal vesicles (synaptic vesicles associated with the active zone within $12 \mathrm{~nm}$ of the plasma membrane) and clathrincoated vesicles. 
To compare the number of membrane-proximal vesicles among the genotypes and among stimulatory and inhibitory conditions, we performed permutation tests and Mann-Whitney U tests.

Electron tomography. Sections (200 nm thick) of Agar 100 embedded organs of Corti were decorated with $10 \mathrm{~nm}$ colloidal gold particles on both surfaces. Tilt series (unidirectional tilt) were then recorded on a Philips CM120 transmission electron microscope at 27,500× magnification using a TVIPS $224 \mathrm{~A}$ slow-scan CCD camera in unbinning mode. The series were calculated using Etomo and the model was created using Imod program (http://bio3d.colorado. edu/). The smallest distance of membrane-proximal vesicles (outer leaflet) to the plasma membrane (inner leaflet) was quantified in the section displaying the closest proximity.

Protein biochemistry. The $\mathrm{C}_{2} \mathrm{~F}$ domain (amino acids 1,688 to 1,927 , NPDK... NEPD) was subcloned as a GST-fusion construct into a pGEX-2T vector. For the pachanga variant, the point mutation was introduced by overlap-PCR using the oligonucleotides 5'-GCC AGC AGG AGG GCA AAC AGG ACA CAG AC-3' and $5^{\prime}$-GTC TGT GTC CTG TTT GCC CTC CTG CTG GC- ${ }^{\prime}$. The subcloned $\mathrm{C}_{2} \mathrm{~F}$ domains were verified by DNA sequencing. Protein expression in BL21-DE3 cells at $16^{\circ} \mathrm{C}$ (overnight) and purification of both constructs were performed in parallel. Cells were pelleted at 5,250 $\mathrm{g}$ and re-suspended in $20 \mathrm{mM}$ Tris- $\mathrm{HCl}$ (pH 7.4), $500 \mathrm{mM} \mathrm{NaCl}, 2.5 \mathrm{mM}$ reduced glutathione, $5 \mu \mathrm{M}$ ATP and $5 \%$ ethanol (vol/vol). Then cells were lysed by sonication with a Branson sonifier 250. Cell debris was pelleted at $23,000 \mathrm{~g}$ and the protein was purified from the supernatant using glutathione Sepharose 4B. The protein was cleaved from the GST-tag with $10 \mathrm{U} \mathrm{ml}^{-1}$ thrombin overnight, whereas the tag remained bound to the Sepharose beads. The protein solution was dialyzed against $20 \mathrm{mM}$ phosphate buffer $\mathrm{pH} 7.4$ (for EDTA runs in Fig. 6h) or 5 mM Tris-HCl pH 7.4 (for EDTA and $\mathrm{Ca}^{2+}$ runs in Fig. 6i-j) at $4{ }^{\circ} \mathrm{C}$, which had been pre-treated with Chelex100 (BioRad). Protein concentration was determined by ultraviolet absorbance at $280 \mathrm{~nm}$.

Circular dichroism spectroscopy was performed on a Chirascan instrument (Applied Photophysics) at $25^{\circ} \mathrm{C}$ with a protein concentration of $0.08 \mathrm{mg} \mathrm{ml}^{-1}$
$(3 \mu \mathrm{M})$ per run. EDTA or $\mathrm{Ca}^{2+}$ was added to a final concentration of $100 \mu \mathrm{M}$, respectively. Ellipticity was measured from $190 \mathrm{~nm}$ to $260 \mathrm{~nm}$, controlling for sufficient light transmission by measuring high tension voltage. All spectra were corrected for buffer contributions.

Autofluorescence was measured in a Fluoromax-3 instrument (Jobin Yvon Horiba) with a protein concentration of $2.36 \mu \mathrm{M}$ with $295-\mathrm{nm}$ excitation wavelength. Fluorescence emission was recorded from 305 to $450 \mathrm{~nm}$ in 1-nm steps with an integration time of $0.2 \mathrm{~s}$, averaging five runs. $\mathrm{Ca}^{2+}$ or EDTA was added to a final concentration of $100 \mu \mathrm{M}$.

Real-time PCR. The apical turns of three to four organs of Corti of Otof Pga/Pga or $\mathrm{Otoff}^{+/+}$mice at postnatal day 14 were dissected and mRNA was extracted by Trizol method. This was repeated three more times for each genotype independently. cDNA synthesis was performed using Superscript II reverse transcriptase in supplied buffer with oligo dT and random hexamers as primers. Real-time PCR was conducted in triplicates for each cDNA sample using an Applied Biosystems SDS 7500 thermal cycler and TaqMan Gene Expression Assays for Otof (Applied Biosystems, Mm00453306_m1) and for the housekeeping genes Pvalb (kindly provided by P. Jonas, Freiburg) and Tbp (Mm00446973_m1). To average $C_{\mathrm{t}}$ values from triplicate experiments, we first calculated a linear value from each $C_{\mathrm{t}}$ value $\left(\right.$ in $\left.=2^{-C \mathrm{t}}\right)$. These linear values were averaged and backtransformed into a $C_{\mathrm{t}}$ value $\left(C_{\mathrm{t} \text {, average }}=-\mathrm{LN}\left(\right.\right.$ lin $\left.\left._{\text {average }}\right) / \mathrm{LN} 2\right)$. Data were analyzed by the $\Delta \Delta C_{\mathrm{t}}$ method.

Data analysis. Data analysis was performed using Matlab, Igor Pro and Image] software. Figures were assembled for display using Adobe Photoshop and Illustrator software. Unless otherwise noted, data are expressed as mean \pm s.e.m. Student's unpaired, two-tailed $t$ test was used to compare two samples unless stated otherwise.

49. Goodman, M.B. \& Lockery, S.R. Pressure polishing: a method for re-shaping patch pipettes during fire polishing. J. Neurosci. Methods 100, 13-15 (2000).

50. McCue, M.P. \& Guinan, J. Jr. Acoustically responsive fibers in the vestibular nerve of the cat. J. Neurosci. 14, 6058-6070 (1994). 